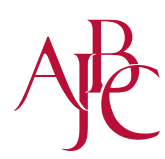

\title{
The Backgrounds and Main Contents of the Revised Guideline for Securing of Research Ethics
}

\author{
In-Jae Lee \\ Department of Ethics Education, Seoul National University of Education, Seoul, Korea
}

Corresponding author: In-Jae Lee, Department of Ethics Education, Seoul National University of Education, 96 Seochojoongang-ro, Seocho-gu, Seoul 06639, Korea

Tel.: +82 234752411

Fax: +82 234752032

Email:ijlee@snue.ac.kr

Received March 10, 2016

Revised March 25, 2016

Accepted March 25, 2016

Published March 30, 2016

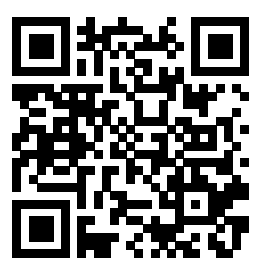

\begin{abstract}
Purpose: This paper focuses on the backgrounds, main contents, and characteristics of the revised guideline for securing of research ethics that allow the researcher and research ethics administrators to understand it well and to properly apply policies. Methods: This revised guideline for securing of research ethics is an amalgamation of comments of research ethics experts, web surveys, public hearings, and forum results by many researchers on the draft of revised guideline. Results: The revised guideline for securing of research ethics manifestation policies ordered by the Ministry of Education has been reformed on November 3, 2015. Conclusion: The guideline for securing of research ethics directed by the Ministry of Education is not only a way of establishing research ethics governance and exhibiting ethics adherence, but also a way of promoting awareness of ethics embedded in the full process of research.
\end{abstract}

Keywords: Research integrity, Researcher's responsibility, Research misconduct, Plagiarism, Improper authorship

\section{Introduction}

오늘날 세계의 많은 국가들은 연구자의 연구부정행위를 예 방하고 바람직한 연구 수행의 문화를 확립하기 위해 관련 규 정의 마련, 연구윤리 교육의 실시, 연구부정행위 검증 절차의 확보 등 다각도의 노력을 기울이고 있다. 연구진실성을 확보 하지 못한 연구의 성과는 누구에게도 신뢰를 받을 수도 없을 뿐만 아니라 국가 사회의 경쟁력을 약화시키기 때문이다. 연 구자의 책임있는 연구수행(responsible conduct of research, $\mathrm{RCR})$ 을 위해 연구자의 윤리의식이 높아져야 할 뿐만 아니라 연구윤리의 시스템 구축 등 전반적인 연구윤리 거버넌스의 확 립이 요청된다. 그리고 이러한 연구윤리 거버넌스 확립에서 가장 기본적으로 역할을 하고 있는 것이 바로 국가 수준의 연 구윤리확보를 위한 지침이라고 말할 수 있다. 우리나라에서도 국가 수준의 연구윤리확보를 위한 지침은 지난 10 여 년 동안 대학 및 연구기관의 연구윤리 거버넌스 구축과 연구윤리 지원
활동의 근거가 되었을 뿐만 아니라 연구자들이 연구 수행 전 과정에서 지켜야 할 것과 해서는 안 되는 것을 인식하고 실천 하는데 중요한 길잡이 역할을 해 왔다. 이러한 국가 수준의 연 구윤리확보를 위한 지침이 갖는 역할을 고려할 때, 이번 지침 이 무슨 이유에서 어떻게 개정되었는지에 대해 관심을 가지고 정확하게 이해하는 것은 연구자에게 필수적으로 요청되는 일 이라고 할 수 있다. 연구자가 개정 지침의 핵심 내용을 제대로 알아야 바람직한 연구 수행을 위해 올바르게 활용할 수 있기 때문이다.

본 논문의 목적은 연구윤리확보를 위한 지침(이하에서는 “연구윤리 지침”으로 칭함.) 개정의 배경과 필요성, 주요 개정 내용 및 특징에 초점을 두어 소개함으로써 대학이나 연구기관의 연구윤리 업무 담당자들이 개정된 지침을 정확 히 이해하여 올바르게 적용하는데 도움을 주고자 하는데 있다. 


\section{The backgrounds and main contents of the revised guideline}

\section{1. 지침 개정의 배경}

우리나라 정부 차원의 연구윤리 지침은 2007년 2월에 제정 된 이후, 몇 번의 부분 개정을 거쳤으며, 현행 연구윤리 지침은 2015년 11월 3일에 교육부 훈령 제 153 호로 개정된 것이다. 필 자는 2014년 9월 15일부터 2015년 9월 30일까지 연구윤리 지 침 개정을 위한 기초 연구의 책임을 맡아 개정 작업을 주도했 다. 이를 위해 관련 선행연구 및 문헌을 검토하고, 연구 현장의 요구를 반영하여 개정(안)을 만들고, 이에 대해 온라인 웹 설문 조사를 통해 대학의 연구윤리 업무 책임 교수, 연구진실성 위원 회 위원장, 연구윤리 업무 실무자와 학술단체의 학회장, 편집위 원장, 연구윤리위원회 위원장, 편집위원 등 1,072 명을 대상으 로 의견을 수렴하였고, 이를 반영한 내용에 대해 다시 공청회, 연구윤리 포럼을 통해 전문가의 의견을 수렴하였다. 이 기초 연 구의 결과를 바탕으로 교육부가 최종적으로 검토하여 현행 연 구윤리 지침으로 확정 - 발표하였다. 또한 필자는 이 개정된 연 구윤리 지침의 해설서를 작성하였는 바, 이하에서 기술하는 지 침 개정의 배경과 필요성, 개정 중점과 특성에 관한 내용은 이 해설서의 내용을 토대로 보완된 것임을 밝혀둔다.

2000년 대 초까지 연구윤리에 대한 인식이 높지 않았고 관 련 지침이 체계적으로 마련되어 있지 않았으나 2005년도 말 황 우석 전 서울대 교수 연구팀의 줄기세포논문 조작 사건을 겪으 면서, 이것이 계기가 되어 과학기술부가 연구윤리 지침을 처음 으로 제정하였다. 이는 이후 대학 등 연구기관의 자율적인 연 구윤리 관련 규정 마련의 토대가 됨으로써 대학 등 연구기관 과 연구자들이 연구윤리에 대한 관심을 높이고 바람직한 연구 윤리의 실천을 위해 노력해야 한다는 인식을 갖도록 하는 계기 가 되었다. 특히, 이 지침에서는 국가로부터 연구비를 지원받는 모든 기관의 경우, 정부의 연구윤리 지침에 근거하여 자율적으 로 자체 연구윤리 관련 규정을 제정하여 운영하고 연구부정행 위를 예방하기 위한 연구윤리 교육을 강화하도록 함으로써 대 학 등 연구기관과 학술단체에서는 연구윤리 관련 규정을 제정 하여 운영해 오고 있으며, 이에 대한 가시적인 효과도 거두었다 (Ministry of Education - National Research Foundation of Korea, 2015).

2014년 연구윤리활동 실태 조사의 결과를 보면, 조사 대상 201 개의 4년제 대학의 경우 $91.0 \%$ 에 해당하는 183 개 대학이 정부의 연구윤리 지침에 따라 연구윤리 관련 규정 혹은 지침을 제정하였다고 응답하였다(NRF, 2015). 이를 통해 연구윤리 관 련 규정이나 지침을 가진 대학은 정부 차원의 연구윤리활동 실 태 조사를 처음 실시한 이래로 꾸준히 증가해 오고 있음을 알 수 있다. 이는 정부의 연구윤리 지침이 대학의 연구윤리 활동
을 활발하게 하는데 일정 정도 기여했다고 평가할 수 있다. 그 러나 이러한 기여에도 불구하고, 현행 연구윤리 지침은 연구 부정행위의 범위에 대해 개념만을 간략하고 포괄적으로 규정 하고 있어 다양한 분야의 연구 현장에서 발생하는 여러 연구윤 리 사안에 대하여 구체적으로 판단하고 적용하고자 할 때, 유 용하고도 실제적인 근거가 되지 못한다는 비판을 받아왔다. 그 동안 제기되었던 기존 연구윤리 지침이 갖는 한계를 정리해 보 면 다음과 같다(Ministry of Education - National Research Foundation of Korea, 2015).

첫째, 기존 연구윤리 지침에서 정의하고 있는 연구부정행위 에 대한 개념 규정이나 범위 등이 다소 추상적이어서 연구현장 에서 연구부정행위를 판단하는 기준으로 활용하는 데에 한계가 있다. 이를테면, 현행 지침 직전의 지침(2014년 교육부 훈령 제 60 호)을 보면, 자신의 이전 저작물을 활용할 때 준수하도록 노 력해야 할 사항을 별도의 조항에서 제시하고 있지만, 중복게재 가 연구부정행위에 속하는지 아닌지에 대해 명확하게 규정하지 않았을 뿐만 아니라, 각 학문 분야별 다양한 사안들에 대해 허 용 가능한 중복게재인지 비난받을 만한 중복게재인지를 판단할 수 있는 실질적인 기준이 되지 못하였다. 또한 부당한 저자 표 시와 관련하여 기존 규정으로는 제자의 학위논문의 지도교수가 이를 활용하여 학술지 논문으로 게재할 때, 누가 제 1 저자가 되 고 공동 저자가 되어야 하는지를 판단하는 데도 실질적인 도움 이 되지 못하였다. 따라서 제 1 저자, 교신저자, 공동저자의 개념 정의와 함께 저자의 순서에 대한 어느 정도 합의 가능한 규정이 필요하였다.

둘째, 기존의 연구윤리 지침은 정부의 지원을 받은 연구 결과 의 연구윤리 문제에만 적용된다는 점은 명확하지만, 학위논문 이나 정부의 지원을 받지 않은 일반적인 연구 결과, 또는 정부 아닌 민간 기관으로부터 지원받은 연구 결과에서의 연구윤리 문제에도 적용되는지에 대하여 명확하게 규정하지 않아 정부의 지원 이외의 광범위한 연구 활동에 이 지침을 적용할 수 있는지 가 모호하였다는 비판도 있었다.

이처럼 연구 현장에서 기존 연구윤리 지침을 적용할 때 겪는 어려움이 많아 개선에 대한 요구가 많았다. 그 중에서 가장 큰 불편함은 기존 연구윤리 지침을 활용하여 제기된 연구부정행위 의 의혹에 대해 판단하고자 할 때 너무 추상적이고 구체적이지 않아 실질적인 도움이 되지 못한다는 것이었다. 따라서 정부 차 원의 연구윤리 지침이 갖는 모호성과 추상성의 문제점을 극복할 수 있도록 연구윤리 지침의 내용을 보다 구체적이고 실질적으로 규정함으로써 연구 현장에서 연구부정행위를 합리적으로 판단 할 수 있는 타당한 기준으로서 폭넓게 활용할 수 있도록 할 필요 가 있다는 점이 제기되었다. 특히, 연구윤리의 국내 · 외 최근 동 향을 반영한 보다 실질적인 연구윤리 지침을 마련함으로써 우리 나라의 연구윤리의 확립에 기여할 수 있도록 할 필요가 있었다. 


\section{2. 개정된 연구윤리 지침의 구성과 개정의 중점}

\section{1) 개정된 연구윤리 지침의 구성과 특징}

개정된 연구윤리 지침은 총 5 장, 33 조로 구성되어 있다. 즉, 제 1 장은 총칙, 제 2 장은 연구자 및 대학 등의 역할과 책임, 제 3 장은 연구부정행위, 제 4 장은 연구부정행위 검증, 제 5 장은 교육 부 소관 연구개발사업에 대한 특칙의 내용으로 되어 있다. 국가 수준의 연구윤리 지침이 지나치게 자주 변경되거나 기존 연구 윤리 지침과의 연속성이 확보되지 못하면 이를 활용하는 연구 자나 연구 기관에서는 번거로움이 크기 때문에 최근의 연구 환 경의 변화와 연구윤리의 국제적 동향 및 연구 현장의 요구 사항 을 고려하면서 꼭 필요한 부분을 위주로 개정하였다. 그러므로 기존 연구윤리 지침에서 개정의 타당한 근거가 없는 조항은 그 대로 유지하면서도 조항 별 내용의 중복성을 해소하고 다른 조 항과의 연계성을 고려하여 필요한 부분에서 조항의 분리, 통합, 보다 적합한 조항으로의 이동을 하였다.

이번에 개정된 연구윤리 지침의 중요한 특징을 다음과 같이 요약해 볼 수 있다. 첫째, 기존의 연구윤리 지침에는 없었던 용 어의 '정의'를 신설하여 개정된 연구윤리 지침에서 사용하는 주 요 용어에 대한 의미를 보다 명확하게 정의함으로써 지침에서 사용하는 주요 용어에 대한 모호함이나 혼동의 여지를 해소하 고자 하였다. 이를테면, 기존의 지침에서 사용된 '데이터'라는 용어가 구체적으로 무엇을 지칭하는 지가 분명하지 않아 연구 의 특성이나 학문 분야별로 혼동할 여지가 많았기 때문에, 연구 원자료와 연구자료, 연구 결과와 연구 결과물을 구분하여 새롭 게 제시하여 보다 명확하게 정의를 내림으로써 이러한 오해를 줄이고자 하였다. 둘째, 국내 - 외의 대학이나 연구기관에서 설 정하고 있는 포괄적인 연구윤리의 영역에 근거하여 연구자 및 대학 등의 역할과 책임을 새롭게 명시하였다. 특히 연구자의 역 할과 책임에 대해서는 모든 학문 분야를 막론하고 연구자에게 기본적으로 요구되는 크게 5 가지 영역을 중심으로 제시하였다. 셋째, 연구부정행위의 범위에 부당한 중복게재를 포함시킴으로 써 기존의 연구부정행위 범위보다 확대하였고, 제기된 연구부 정 의혹에 대하여 그것이 연구부정행위에 속하는지를 보다 명 확하게 판단할 수 있도록 표절, 부당한 저자표시, 부당한 중복 게재의 구체적인 판단 기준을 제시하였다.

\section{2) 개정된 연구윤리 지침의 목적}

개정된 연구윤리 지침은 연구자 및 대학 등의 연구윤리를 확보하기 위한 기본적인 원칙과 방향을 정하고, 연구부정행 위를 방지하기 위한 데 그 목적이 있음을 명시하고 있다. 기 존 연구윤리 지침이 교육부 소관 연구개발사업을 추진 - 관리 하거나 수행하는 대학 및 연구기관 그리고 학술단체의 연구부 정행위를 방지하는데 기본 목적이 있었다면, 개정된 연구윤 리 지침은 이를 포함하고 더 나아가 학술진흥법에서 규정한 모
든 학술활동(학위논문 발표, 정부의 지원을 받지 않는 연구활 동 등)에서의 연구윤리의 확립을 목적으로 하고 있다(Ministry of Education - National Research Foundation of Korea, 2015).

\section{3) 적용 대상}

기존의 연구윤리 지침 적용 대상은 〈학술진흥법〉 제 5 조에 따 른 학술지원 사업 및 교육부 소관 연구개발에만 국한됨으로써 학위논문이나 교육부 이외의 국가기관 및 국가 이외의 외부로 부터 지원받은 과제의 연구윤리 문제에는 어떤 지침을 적용해 야 하는지가 명확하지 않아 적용에 어려움이 많았다는 비판을 받아왔다. 따라서 개정된 연구윤리 지침은 이를 해소하기 위해 연구윤리 지침의 적용 대상과 방법을 다음과 같이 3 가지 측면 으로 구분하여 제시하고 있다.

첫째, 교육부의 연구비를 지원받아 수행된 사업의 연구 결과 에 연구윤리의 문제가 발생하였을 때는 본 개정된 연구윤리 지 침의 제 $2,3,4,5$ 장을 적용한다. 즉, 교육부의 직접 지원을 받 는 사업과 교육부 소관의 연구개발 사업, 그리고 기타 교육부 장관이 필요하다고 인정하는 연구 사업에서의 연구윤리 문제는 이 지침을 의무적으로 적용한다는 것이다.

둘째, 대학 등과 전문기관 자체의 연구활동, 교육부 이외의 국가기관 및 국가 이외의 외부기관으로부터 지원받은 과제의 연구윤리 문제에 대해서는 본 개정된 지침의 제 $2,3,4$ 장을 토 대로 자체적인 연구윤리 지침을 제정하여 시행할 수 있다고 명 시하였다. 그런데 만일 이 사안에서 자체적인 연구윤리 지침이 없을 경우에는 본 개정된 연구윤리 지침의 제 $2,3,4$ 장을 적용 할 수 있다. 이는 대학 등과 전문기관이 자체적인 연구윤리 지 침을 제정하고자 할 때나 자체적인 지침이 없으면서 대학 등과 전문기관의 자체적인 연구활동, 교육부 이외의 국가기관 또는 국가 이외의 외부기관으로부터 지원받은 과제의 연구윤리 문제 에 대해서는 이 지침이 기본 모델이 될 수 있음을 명시하고 있 다. 여기서 '대학 등 및 전문기관 자체의 연구활동'이란 학위논 문 발표, 대학 등 및 전문기관의 자체 예산으로 수행되는 연구 등을 포함하고, '교육부 이외의 국가기관 및 국가 이외의 외부 기관으로부터 지원받은 과제'란 교육부를 제외한 국기기관, 기 업 및 민간 단체로부터 수탁받은 연구 등을 말한다.

4) 연구자, 대학 등, 전문기관별 각각의 역할과 책임 명시

연구자, 대학 등, 전문기관별로 각각의 역할과 책임에 대해 새롭게 구체적으로 규정하고 있다. 특히 연구자의 경우, 인간대 상 및 동물 실험에서의 윤리, 연구진실성 확보, 연구자의 사회 적 책임, 투명하고 공정한 연구비의 사용, 이익충돌에서의 책임 등 광의의 연구윤리의 세부 영역에서 요구되는 역할과 책임을 포함하고 있다. 


\section{5) 연구윤리 교육}

대학 등과 전문기관에서는 연구윤리 확립을 위해 연구자를 대상으로 연구윤리교육을 지속적으로 할 것을 강조하고 있다. 특히 교육부의 지원을 받아 연구를 수행하는 연구자는 반드시 연구윤리 교육을 이수해야 함을 명시하고 있다.

\section{6) 자체 연구윤리 지침 마련 및 검증 체계 확립}

대학 등 및 전문기관은 본 지침 개정(안)을 토대로 각각 실정 에 따라 자체의 연구윤리 지침을 마련하고 연구부정행위에 대 한 공정한 검증과 바람직한 연구수행 활동을 확산하도록 규정 하고 있다.

\section{7) 연구부정행위}

연구부정행위와 관련하여 기존의 연구윤리 지침과 비교할 때, 개정된 연구윤리 지침이 갖는 대표적인 3 가지 특징은 다음 과 같다. 첫째, 연구부정행위의 개념에 대하여 보다 명확하게 정의하였다. 이를테면, '위조'의 경우는 “존재하지 않는 연구 원 자료 또는 연구자료, 연구결과 등을 허위로 만들거나 기록 또 는 보고하는 행위”라고 규정하였는데, 이는 기존 지침에서 모호 하게 사용되던 데이터를 연구 원자료와 연구자료로 보다 세분 화한 것이다. 여기서 연구 원자료란 "연구 목적을 달성하기 위 해 연구자가 실험, 관찰, 조사 등을 거쳐 수집한 가공 이전의 자 료와 문헌 등”을 말하는 것으로, 연구자료란 “연구 원자료를 가 공한 자료와 이를 활용한 2 차 자료 및 문헌"을 의미하는 것으로 데이터의 특성과 범위를 구체적으로 제시하였다. 또한 '표절'의 경우, 기존의 지침에서는 "타인의 아이디어, 연구 내용-결과 등을 적절한 인용 없이 사용하는 행위"라고 했던 것을 "일반적 지식이 아닌 타인의 독창적인 아이디어 또는 창작물을 적절한 출처표시 없이 활용함으로써, 제 3 자에게 자신의 창작물인 것처 럼 인식하게 행위”라고 규정함으로써, 의도적이든 비의도적이 든 출처표시가 꼭 필요한 때(타인의 독창적인 아이디어나 창작 물)에 적절하게 출처표시를 하지 않았을 때 표절이 성립한다는 점을 부각시키고 있다.

둘째, 연구부정행위의 범위를 위조, 변조, 표절, 부당한 저자 표시, 부당한 중복게재, 연구부정행위에 대한 조사 방해 행위, 각 학문분야에서 통상적으로 용인되는 범위를 벗어나는 행위 등 7 가지로 규정했는데, 이는 기존의 지침에 비해 '부당한 중복 게재'가 추가된 것이다. 이렇게 한 이유는 그 동안 우리나라 학 계에서 끊임없이 논란이 되어 온 중복게재의 문제점을 조금이 라도 해소하는데 도움을 주기 위한 것이라고 볼 수 있다. 다만 중복게재의 유형 중에는 이차게재(secondary publication)처 럼 비난의 여지가 없이 정당화될 수 있는 것도 있고, 연구의 특 성이나 학문 영역에 따라 중복게재의 허용 범위에서의 차이가 워낙 다양하여 어떤 획일적인 기준을 일방적으로 적용할 수 없
는 난점이 있기 때문에 어느 경우에도 연구윤리의 측면에서 인 정할 수 없다고 합의가 가능한 최소한의 것만을 '부당한 중복게 재’라는 용어를 사용하여 연구부정행위 속에 포함시킨 것이다. 따라서 '부당한 중복게재’란 “연구자가 자신의 이전 연구결과와 동일 또는 실질적으로 유사한 저작물을 출처표시 없이 게재한 후, 연구비를 수령하거나 별도의 연구업적으로 인정받는 경우 등 부당한 이익을 얻는 행위”라고 규정했다. 즉, 첫째, 연구자 자신의 이전 연구 내용과 동일 또는 실질적으로 유사한 저작물 을 출처표시를 하지 않아 처음 발표한 것처럼 하고, 둘째, 이를 통해 연구비 수령, 별도의 연구업적으로 인정받음과 같이 부당 한 이익을 얻는 경우 등 두 가지 요건을 모두 충족하였을 때에 만 부당한 중복게재라고 하고 이를 연구부정행위로 판단한다는 것이다.

셋째, 표절, 부당한 저자표시에 대한 구체적인 판단 기준을 제시하고 있다. 이는 그 동안 대학이나 다른 연구 기관에서 표 절이나 부당한 저자표시를 판단하기 위해 참조할 수 있는 타당 한 근거가 없어 어려움이 많았기에 이를 해소할 수 있는 구체적 인 판단 기준을 예시해야 할 필요성이 있다는 연구 현장의 요구 를 반영한 것이다. 따라서 다음과 같이 표절과 부당한 저자표 시를 판단할 수 있는 대표적인 기준으로 각각 4 가지와 3 가지를 예시하고 있는데 이를 살펴보면 다음과 같다.

\section{(1) 표절 판단 기준}

i . 타인의 연구내용 전부 또는 일부를 출처를 표시하지 않고 그대로 활용하는 경우

ii. 타인의 저작물의 단어 - 문장구조를 일부 변형하여 사용 하면서 출처를 표시하지 않는 경우

iii. 타인의 독창적인 생각 등을 활용하면서 출처를 표시하지 않은 경우

iv. 타인의 저작물을 번역하여 활용하면서 출처를 표시하지 않은 경우

(2) 부당한 저자표시 판단 기준

i . 연구내용 또는 결과에 대한 공헌 또는 기여가 없음에도 저자 자격을 부여하는 경우

ii. 연구내용 또는 결과에 대한 공헌 또는 기여가 있음에도 저자 자격을 부여하지 않는 경우

iii. 지도학생의 학위논문을 활용하여 학술지 등에 논문을 게 재할 때, 지도교수의 단독 명의로 하거나, 타당한 근거없이 지 도교수를 제 1 저자로 하거나 제 3 자를 공동저자로 하는 경우

여기서 부당한 저자표시 판단 기준의 하나인 (2)-iii과 관련 하여 부연 설명을 하면, 제자의 학위논문을 바탕으로 학술지 논 문으로 게재할 경우, 지도교수는 공동저자로서 등재하는 것이 
타당하다는 것이다. 물론 학위논문에 근거하고 있지만, 여기에 데이터의 추가 및 새로운 관점이나 해석이 가미되는 등 학위논 문의 내용보다 학술적으로 의미있는 부분이 추가되었고, 이러 한 역할을 지도교수가 하였다면, 그리고 그 기여가 제 1 저자 또 는 주저자의 자격에 합당한 것이라면 지도교수가 제 1 저자가 되 고 제자가 공동저자가 될 수 있다. 그러나 이 경우를 제외하면, 즉, 학술지 게재 논문이 학위논문의 내용과 동일하거나 실질적 으로 유사하다면, 지도교수가 단독 저자가 되거나 학위논문 작 성 때나 학술지 게재 논문으로 전환하는 과정에서 저자로서의 실질적 기여가 없는 제 3 자가 저자로 등재되는 것은 부당한 저 자표시로서 연구부정행위에 속한다는 것이다.

개정된 연구윤리 지침에서 표절, 부당한 저자표시, 부당한 중 복게재인지 아닌지를 판단하기 위해 위에서 언급한 판단 기준 에 대해 연구자마다 학문 분야에 따라 여전히 논란은 있을 수 있다. 그렇지만 연구 현장에서 종종 제기되는 연구부정행위 의 혹 제보에 대해 제대로 판단할 수 있는 구체적이고 실질적인 예 시로써 어떤 학문 분야에서든지 크게 이의없이 공통적으로 적 용할 수 있는 최소한의 판단 기준을 제시한 것이라고 할 수 있 다.

다른 한편 개정된 연구윤리 지침에서는 제보된 연구부정행위 에 대해 정해진 규정과 절차에 따라 공정하게 검증하되 최종 판 단을 할 때 일반적으로 고려해야 할 사항을 상세히 제시함으로 써 연구부정행위 판단에서의 어려움을 해소하는데 도움을 주고 자 한 점도 중요한 특징 중의 하나이다. 즉, 연구부정행위를 검 증하고 판단할 때 다음의 사항들을 종합적으로 고려하여 신중 하게 판단해야 한다. 첫째, 제보된 연구부정행위가 연구자가 속 한 학문분야에서 윤리적, 법적으로 비난받을 만한 행위인지, 둘 째, 해당 행위 당시 연구윤리 지침이나 보편적인 기준이 있었는 지, 있었다면 무엇이었는지, 셋째, 행위자의 고의, 연구부정행 위 결과물의 양과 질, 연구부정행위를 통해서 얻은 이익 등이 바로 그것이다.

개정된 연구윤리 지침 중 제 1 장 총칙의 제 2 조(정의), 제 3 조 (적용대상 및 방법), 제 2 장 연구자 및 대학 등의 역할과 책임 의 제 5 조(연구자의 역할과 책임), 제 3 장 연구부정행위의 제 12 조(연구부정행위의 범위), 제 13 조(연구부정행위 판단)가 기존의 연구윤리 지침에 비해 대폭 개정되었거나 보완되었다 면, 제4장 연구부정행위 검증, 제5장 교육부 소관 연구개발 사업에 대한 특칙은 상대적으로 소폭의 일부의 수정이 이루 어졌다. 개정이 이루어진 조항을 중심으로 이를 설명하면 다 음과 같다.

\section{8) 본조사위원회 구성}

본조사의 공정성과 객관성을 확보하기 위해 본조사위원 전 체에서 외부인의 비율을 $30 \%$ 이상으로 하고, 조사위원회에
해당 학문분야의 전문가가 $50 \%$ 이상으로 되도록 하되, 이 중 소속이 다른 외부 전문가를 1 인 이상 반드시 포함되도록 하 였다. 여기서 '해당 학문분야의 전문가'란 일률적으로 기준 을 제시하기가 쉽지 않지만, 통상 해당 연구분야의 전공자 또 는 과거에 유사한 연구를 수행한 실적이 충분하거나 현재에 연구를 수행하고 있는 자라고 말할 수 있을 것이다(Ministry of Education - National Research Foundation of Korea, 2015).

\section{9) 검증 절차}

개정된 연구윤리 지침 제 18 조(연구부정행위 검증 절차) 4 항 에서 대학 등의 장이 연구부정행위를 제보받아 검증하였을 때 에는 그 결과를 해당 연구자의 소속 기관 및 해당 논문 발간 학 술단체에 통보하도록 하였다. 이는 연구부정행위가 관련 기관 에 정확하게 알려짐으로써 연구부정행위 결과가 계속해서 잘못 사용되는 것을 막고, 연구부정행위와 다른 연구자들에게 경각 심을 일깨워 유사한 연구부정행위가 재발하지 않도록 하기 위 한 것이라고 볼 수 있다.

10) 이의신청 후 재조사 요청 및 재조사 시한 설정

제 5 장 제 28 조(재조사)에서 규정하고 있듯이, 재조사의 경우, 이의신청을 거친 후에 재조사를 요청할 수 있도록 하였는 바, 이는 기존 연구윤리 지침에서 '이의신청과는 별도로 동시에 재 조사를 할 수 있었던' 것을 개정한 것이다. 또한 이의신청 결과 수령 후 30 일의 재조사 요청 기간을 설정함으로써 의도적으로 재조사를 지연하는 것을 예방하고자 하였다.

\section{1) 후속조치}

제 30 조(조사결과에 대한 후속조치)는 "교육부장관은 통보 받 은 조사 결과가 연구부정행위로 판단되는 경우에는 연구부정행 위자에 대한 징계 요구, 학술진흥법 제 19 조 및 제 20 조에 의한 사업비 지급 중지 및 환수, 학술지원대상자 선정 제외 등의 후 속조치를 취할 수 있으며, 이를 연구자의 소속기관에 통보하여 야 한다"고 규정하고 있다. 이는 연구부정행위로 최종 판정된 것에 대하여 대학 등이 자체적으로 적절한 조치를 취할 것을 의 무로 규정함으로써 연구에 대한 신뢰성을 높이고 개별 기관 내 부의 공모나 묵인에 의해 연구부정행위가 방조되는 것을 방지 하고자 하였다.

부칙 제 2 조(소급 적용)에서는 개정된 연구윤리 지침의 소급 적용에 관한 사항을 신설하여 개정된 연구윤리 지침 이전의 사 안에 대해서는 당시의 규정이나 학계에서 통용되는 관례에 따 르게 함으로써, 개정된 연구윤리 지침의 적용 시점에 대한 논란 의 소지를 제거하고자 하였다. 


\section{Conclusion}

지금까지 2015년 11월 3일자로 개정된 교육부의 연구윤리 지침이 개정된 배경과 필요성, 개정의 중점과 주요 내용 및 특 징에 대해 살펴보았다. 개정된 이 연구윤리 지침의 중요한 특징 은 지침의 주요 용어를 명확하게 정의하고 있는 점, 적용 대상 과 방법을 보다 구체적으로 제시하고 있는 점, 연구 수행 전 과 정에서 연구자의 역할과 책임을 밝히면서 지속적으로 연구윤리 교육을 받아야 한다는 점을 명시한 점, 연구부정행위의 범위 속 에 '부당한 중복게재'를 추가하고, 각각의 연구부정행위에 대한 개념 규정을 보다 명료히 하면서 표절과 부당한 저자표시를 판 단할 수 있는 구체적인 기준을 예시하고 있고 연구부정행위를 판단할 때 종합적으로 고려해야 할 사항을 새롭게 제시한 점 등 에서 찾아볼 수 있다.

연구윤리 지침 속에는 연구자로서 추구하고 따라야 할 올바 른 연구의 방향(책임있는 연구수행)과 해서는 안되는 연구부정 행위의 범위, 만일 연구부정행위가 발생하였을 때 어떻게 제보 하고, 검증하고, 사후 조치를 취할 것인가에 대해 안내하고 있 다. 따라서 연구자는 교육부의 이 지침이 왜 개정되었고 어디에 중점이 있는지를 제대로 알고 연구 수행 전 과정에서 이를 자율 적으로 지켜야 한다. 뿐만 아니라 대학과 다른 연구기관에서는 교육부의 이 지침을 토대로 자체 지침을 제정, 보완하고 구성원 들에게 널리 홍보함으로써 새롭게 바뀐 연구윤리 지침의 활용
에서 문제가 없도록 해야 한다. 특히, 각 학술단체에서는 개정 된 교육부의 연구윤리 지침을 정확히 이해하여 기존의 자체 지 침이 있는 경우 수정 및 보완해야 할 것이고, 아직까지 지침을 마련하지 않은 경우, 이를 토대로 제정하여 활용해야 한다. 특 히, 학술대회나 뉴스레터 또는 학술지 등에 개정된 연구윤리 지 침에 대해 소개함으로써 학회 구성원들이 바뀐 연구윤리 지침 을 정확히 알고 올바르게 활용할 수 있도록 해야 한다.

\section{References}

Kim JH. A Study on Survey and Analysis of Research Ethics Activities and Illegal Cases in Korea. National Research Foundation of Korea, Seoul, pp108-109, 2015.

Ministry of Education - National Research Foundation of Korea. Manual on the Guideline for Securing of Research Ethics. National Research Foundation of Korea, Seoul, pp2-4, 2015.

Ministry of Education - National Research Foundation of Korea. Manual on the Guideline for Securing of Research Ethics. National Research Foundation of Korea, Seoul, pp55-63, 2015. 


\section{국문초록}

\section{연구윤리 확보를 위한 개정 지침의 주요 내용 및 개정 배경}

이인재

서울교육대학교 윤리교육과, 서울, 한국

목적: 본 논문의 목적은 연구자나 연구윤리 업무 담당자들이 개정된 연구윤리 지침을 정확히 이해하여 본 지침을 올바르게 적용할 수 있도록 하기 위해 지침 개정의 배경과 필요성, 개정 중점과 주요 내용 및 특징에 초점을 두어 소개하는데 있다.

방법: 개정된 연구윤리 지침은 정책과제 연구진이 마련한 기본 안에 대해 연구윤리 전문가 자문, 대학 및 학회의 연구윤리 업무 책 임자와 실무자를 대상으로 온라인 설문조사, 공청회, 연구윤리 포럼 등을 통해 다양한 의견을 수렴하여 반영하여 이루어졌다.

결과: 교육부의 훈령인 연구윤리확보를 위한 지침이 2015년 11 월 3일에 개정되었다.

결론: 국가의 연구윤리확보를 위한 지침은 대학 및 연구기관의 연구윤리 거버넌스 구축과 연구윤리 지원 활동의 근거가 될 뿐만 아 니라 연구자들이 연구 수행 전 과정에서 지켜야 할 것과 해서는 안 되는 것을 인식하고 실천하는데 방향키의 역할을 하고 있다.

핵심어: 연구진실성, 연구자의 책임, 연구부정행위, 표절, 부당한 저자표시

\section{참고문헌}

김정희. 국내 연구윤리활동 실태 및 부정사례 조사연구. 한국연구재단, 서울, pp108-109, 2015. 교육부 · 한국연구재단. 연구윤리 확보를 위한 지침 해설서. 한국연구재단, 서울, $\mathrm{pp} 2-4,2015$. 교육부 · 한국연구재단. 연구윤리 확보를 위한 지침 해설서. 한국연구재단, 서울, pp55-63, 2015. 


\section{中文摘要}

\section{保障研究伦理的指导方针修订版及其修改背景}

李仁宰

首尔教育大学校, 伦理教育科, 首尔, 韩国

目的: 重点介绍修改研究伦理指导方针的背景和其必要性, 并阐述了重点修改部分、主要内容和指导方针的特正, 以至让研究人 员和研究伦理管理员能够很好地理解并正确运用政策保障。

方法: 研究伦理的修订版指导方针是通过研究者向研究伦理专家咨询, 对大学、学会的研究伦理业务负责人及工作人员进行网 络调查, 公开听证会, 论坛和评论的结果聚合而成。

结果: 2015年11月3日由教育部下令对研究伦理体现政策指导方针进行了修改。

结论: 保障国家的研究伦理的指导方针不仅建立大学及研究机关的研究伦理, 也成为研究伦理资源活动的依据, 也是在研究过 程中推动嵌入式的道德意识的一种方式。

关键词: 科研诚信, 研究者的责任, 科研不端行为, 剽窃, 署名不当 